\title{
Language in Schizophrenia and Aphasia: the Relationship with Non-verbal Cognition and Thought Disorder
}

Bethany Little ${ }^{1}$, Peter Gallagher ${ }^{1}$, Vitor Zimmerer ${ }^{2}$, Rosemary Varley ${ }^{2}$, Maggie Douglas $^{3,1}$, Helen Spencer ${ }^{3,1}$, Derya Çokal ${ }^{1,6}$, Felicity Deamer ${ }^{4,7}$, Douglas Turkington ${ }^{1,3}$, I. Nicol Ferrier ${ }^{1}$, Wolfram Hinzen ${ }^{5,8,9}$ and Stuart Watson ${ }^{1,3}$

${ }^{1}$ Institute of Neuroscience, Newcastle University, Newcastle upon Tyne, UK

${ }^{2}$ Division of Psychology and Language Sciences, University College London, London, UK

${ }^{3}$ Northumberland, Tyne and Wear NHS Foundation Trust, Newcastle upon Tyne, UK

${ }^{4}$ Department of Philosophy, Durham University, Durham, UK

${ }^{5}$ ICREA (Catalan Institute of Advanced Studies and Research)/Universitat Pompeu Fabra, Barcelona, Spain Corresponding author: Wolfram Hinzen, Universitat Pompeu Fabra, Departament de Traducció i Ciències del Llenguatge, Roc Boronat, 138, 08018 Barcelona, Spain. wolfram.hinzen@gmail.com

Additional affiliations

${ }^{6}$ School of Electronic Engineering and Computer Science, Cognitive Science Research Group, Queen Mary University of London, London

${ }^{7}$ Department of English Studies, Durham University, Durham, UK

${ }^{8}$ Department of Translation and Language Sciences, Universitat Pompeu Fabra, Barcelona, Spain

${ }^{9}$ FIDMAG Germanes Hospitalaries Research Foundation, Benito Menni Hospital, Barcelona, Spain 


\section{Abstract}

Objective: To determine the relationship between language abnormalities and broader cognitive impairment and thought disorder by examining language and cognition in schizophrenia and aphasia (a primary language disorder).

Methods: Cognitive and linguistic profiles were measured with a battery of standardised tests, and compared in a clinical population of $n=50$ ( $n=30$ with schizophrenia and $n=20$ with aphasia) and $n=61$ non-clinical comparisons ( $n=45$ healthy controls and $n=16$ non-affected first-degree relatives of patients with schizophrenia).

Results: Both clinical groups showed linguistic deficits. Verbal impairment was more severe in participants with aphasia, whereas non-verbal performance was more affected in participants with schizophrenia. In schizophrenia, but not in aphasia, verbal and non-verbal performance were associated. Formal thought disorder was associated with impairment in executive function and in grammatical, but not naming, tasks.

Conclusion: While patients with schizophrenia and aphasia showed language impairments, the nature and cognitive basis of these impairments may be different; language performance disassociates from broader cognitive functioning in aphasia but may be an intrinsic expression of a broader cognitive impairment in schizophrenia. Thought disorder may represent a core malfunction of grammatical processing. Results suggests that communicative ability may be a valid target in cognitive remediation strategies in schizophrenia.

Keywords: schizophrenia; aphasia; thought disorder; language; cognition 


\section{Introduction}

Patients with schizophrenia typically show widespread cognitive impairment, spanning verbal and non-verbal abilities (Reichenberg \& Harvey, 2007; Schaefer, Giangrande, Weinberger, \& Dickinson, 2013). There appear to be particular deficits in executive function (EF) and semantic processing (Doughty \& Done, 2009; Lawrence, Doughty, Al-Mousawi, Clegg, \& Done, 2007; Reichenberg \& Harvey, 2007), which appear independent of a generalised cognitive impairment (Weickert et al., 2000). Cognitive impairment is consistently found across various assessment methods and cultures (Schaefer et al., 2013) and in those at high risk of schizophrenia, including unaffected first-degree relatives (FDRs) of patients with schizophrenia (Bora et al., 2014). It is arguably a core component of the disorder and is associated with poor functioning and decreased quality of life (Mohamed et al., 2008; Sheffield et al., 2014). Formal thought disorder (FTD) refers to disorganised thought as evidenced by abnormal speech (Roche, Creed, Macmahon, Brennan, \& Clarke, 2015), and seems to be associated with greater cognitive deficit in schizophrenia, particularly in semantic processing and EF (Bora, Yalincetin, Binnur, \& Alptekin, 2019; Stirling, Hellewell, Blakey, \& Deakin, 2006).

Schizophrenia, particularly in those with FTD (Barrera, McKenna, \& Berrios, 2005; RodriguezFerrera, McCarthy, \& McKenna, 2001; Tan, Yelland, \& Rossell, 2016), is also associated with a range of abnormalities in language production and comprehension, including impaired phonology, semantics, grammar, syntax, and pragmatic ability (Bambini et al., 2016; Condray, Steinhauer, van Kammen, \& Kasparek, 2002; DiSimoni, Darley, \& Aronson, 1977). Deficits in lexical-semantic retrieval are apparent, with some evidence of impaired naming ability (Leeson, Laws, \& McKenna, 2006), and studies demonstrate abnormal speech patterns, including aberrant use of pronouns, abnormal syntactic structure, and reduced sentence complexity (Condray et al., 2002; DeLisi, 2001; Fineberg et al., 2015; Kuperberg, 2010; Oh, McCarthy, \& McKenna, 2002; Stirling et al., 2006). Poverty of content of speech (e.g. empty speech, alogia), incoherence (e.g. word salad, incomprehensible speech), and neologisms and word approximations (making up new words) have also been reported in people with schizophrenia (McKenna \& Oh, 2005). Language impairment in schizophrenia is consistent across cultures (Kim et al., 2015; Sumiyoshi et al., 2005), is associated with poor functioning and quality of life (Bowie \& Harvey, 2008; Tan, Thomas, \& Rossell, 2014), and is found in FDRs (Bedi et al., 2015). However, the exact picture of the language impairment is unclear, particularly in naming ability and sentence comprehension, where some studies find impairments in people with schizophrenia (with and without FTD), while others do not (Barrera et al., 2005; Bora et al., 2019; Goldberg et al., 1998; Leeson et al., 2006; Rodriguez-Ferrera et al., 2001; Stirling et al., 2006).

These language abnormalities have led some to characterise schizophrenia as a disorder of language, with linguistic impairments and disorganisation playing a causal role in the pathogenesis of schizophrenia and in symptoms in other apparently non-linguistic domains such as altered perceptions (Crow, 2008; Hinzen \& Rosselló, 2015; Landre, Taylor, \& Kearns, 1992; Tan et al., 2016; Zimmerer, Watson, Turkington, Ferrier, \& Hinzen, 2017). It has been argued that thought in humans is intrinsically linguistic (Hinzen, Rosselló, \& McKenna, 2016) and that linguistic abnormalities play a causal role in the development of FTD and delusions (Hinzen \& Rosselló, 2015). These include loss of the referent in noun phrases, reduced syntactic complexity, including fewer clausal combinations, a lack of clausal embedding, and reduced figurative language (Çokal et al., 2018; Fraser, King, Thomas, \& Kendell, 1986; Oh et al., 2002; Sevilla et al., 2018; Titone, Libben, Niman, Ranbom, \& Levy, 2007). The apparent association of the origin of schizophrenia with the evolution of human language has been cited as providing further support for the 
pathogenic salience of language impairments (Crow, 2008; Palaniyappan et al., 2013). In line with this, patients with schizophrenia and FTD show altered structure and activation in brain areas associated with language (Kircher, Oh, Brammer, \& McGuire, 2005; Li et al., 2007).

An alternative view is that the language abnormalities in schizophrenia are an expression of disordered thinking (Bleuler, 1950) or cognitive impairment, particularly disorganised semantic memory (Goldberg et al., 1998; Leeson et al., 2006; Sumiyoshi et al., 2005), working memory and EF (Harrow et al., 2003; Kuperberg, 2010; Rodriguez-Ferrera et al., 2001). However, there is a complex interplay between language and non-verbal cognition. For example, inner speech and phonological working memory may be important in some cognitive tasks (Clark, 1998) and may underpin complex reasoning (Baldo et al., 2005). Language processing is also integrated with aspects of EF such as inhibition and there is a close relationship in their underpinning neural mechanisms (Fedorenko \& Varley, 2016).

This debate regarding the necessary role of language in thought (Crow, 1998; Fedorenko \& Varley, 2016; Kleist, 1914) invites comparison with aphasia, a primary language impairment resulting from brain injury. Typically, people with aphasia achieve lower EF and memory scores than neurotypical controls and some studies suggest that aphasia severity correlates with non-verbal cognitive performance (Baldo, Paulraj, Curran, \& Dronkers, 2015; Fonseca, Ferreira, \& Martins, 2017). However, there are also cases of people with severe aphasia who, on carefully designed tasks that remove demand for language processing, display intact thinking processes (Willems, Benn, Hagoort, Toni, \& Varley, 2011). These results might suggest considerable autonomy between language and reasoning (Varley, 2014). Speech and language abnormalities observed in schizophrenia and FTD, are reported to be similar to those found in fluent, semantic aphasia (Faber et al., 1983; Landre et al., 1992; Taylor, 1999). Patients with schizophrenia and FTD tend to score below average on aphasia batteries (Dickerson, Boronow, Ringel, \& Parente, 1999), display verbal comprehension deficits (DiSimoni et al., 1977; Halpern \& McCartin-Clark, 1984) and impairment in semantic sorting tasks (Kelter, Cohen, Engel, List, \& Strohner, 1977) that are similar to those of aphasic patients, and show structural and functional abnormalities in brain areas associated with aphasia (Kircher et al., 2001; Palaniyappan et al., 2013; Sans-Sansa et al., 2013).

One way to shed light on the potentially causal role of language disruption on thought and cognition, then, would be to directly compare patients with schizophrenia with (SZ+FTD) and without (SZFTD) FTD, and patients with aphasia, on a range of verbal and non-verbal cognitive domains that are considered to be impaired in schizophrenia: intelligence, EF, semantic memory, sentence comprehension, and naming (Barrera et al., 2005; Leeson et al., 2006; Rodriguez-Ferrera et al., 2001; Schaefer et al., 2013; Stirling et al., 2006). Since FDRs tend to show moderate cognitive impairment, it is also of interest to test this group. We hypothesised that: $\mathrm{H} 1$ ) schizophrenia would be associated with deficits across all tests and FDRs would show smaller impairments; H2) SZ+FTD would score lower than SZ-FTD and controls on all tests; H3) the verbal profile in aphasia would mirror the SZ+FTD profile more closely than the SZ-FTD profile (i.e. there will be fewer group differences between aphasia and SZ+FTD as compared to aphasia vs SZ-FTD on verbal tasks) and $\mathrm{H} 4$ ) verbal performance would correlate with non-verbal performance in both schizophrenia groups but less so in aphasia. 


\section{Materials and Methods}

\section{Participants}

Thirty patients with schizophrenia were recruited from Northumberland Tyne and Wear NHS Mental Health Foundation Trust through care coordinators. Inclusion criteria comprised a diagnosis of schizophrenia in line with DSM-IV (American Psychiatric Association, 2000) criteria and a score $\geq 60$ on the Positive and Negative Syndrome Scale (PANSS; a measure of global symptom severity) (Kay, Fiszbein, \& Opler, 1987). Degree of FTD was measured with the Conceptual Disorganisation (CD) question of the PANSS, which specifies a "disorganised process of thinking characterised by disruption of goal directed sequencing e.g. circumstantiality, tangentiality, loose associations, non sequiturs, gross illogicality, or thought block". CD is rated on a scale of 1 (Absent) to 7 (Extreme). The SZ+FTD group comprised 15 patients with moderate to severe FTD (CD score $\geq 4$ ) and the SZ-FTD group comprised 15 patients with, at most, minimal FTD (CD score < 4). Sixteen age-matched FDRs of patients with schizophrenia and 15 agedmatched healthy controls $(\mathrm{HC})$ with no history of psychosis were recruited via community-based groups. Exclusion criteria for all participants included: a primary diagnosis of alcoholism or substance dependence; pervasive developmental disorder interfering with language skills; organic disease of the brain including significant head injury, stroke, tumour and epilepsy; and severe dyslexia.

Twenty patients diagnosed with aphasia following left hemisphere stroke were recruited through University College London's (UCL) communication clinic and UK Connect. All were in the chronic phase of recovery (mean 76.2 months post-onset; SD=63.3). This group were older than the schizophrenia group, so 30 controls age-matched to the aphasia patients were recruited from community-based groups in London. All participants were native English speakers, aged 16 and above, had normal, or corrected-to-normal, vision, and reported either no, or corrected, hearing impairment. A favourable ethics opinion was obtained from the National Research Ethics Service Committee North East - Newcastle and North Tyneside 2 and UCL Ethics Committee. Written informed consent was obtained from each participant.

\section{Materials and Measures}

For participants with schizophrenia and matched HCs, the National Adult Reading Test (NART; Nelson \& Willison, 1991) was used to estimate premorbid intelligence (pmIQ). The Wechsler Abbreviated Scale of Intelligence - Second Edition (WASI-II; Wechsler, 2011) was used to measure current intelligence, which incorporates non-verbal intelligence (Perceptual Reasoning Index; PRI; calculated from Block Design and Matrix Reasoning sub-test scores) and verbal intelligence (Verbal Comprehension Index; VCl; calculated from Vocabulary and Similarities sub-test scores). Block Design requires participants to recreate a design using coloured blocks within a time limit, measuring visuospatial capacity and abstract reasoning. In Matrix Reasoning, participants complete a series of visual matrices, measuring abstract problem solving. WASI-II Vocabulary evaluates word knowledge and verbal concept formation through picture naming and word meaning definition. In Similarities, participants select words describing objects that share common characteristics with a target object and describe how two words are similar in meaning, measuring verbal concept formation and reasoning.

The Brixton Spatial Anticipation Test (Burgess \& Shallice, 1997) was used as a non-verbal measure of EF. In this task, participants view arrays of circles of which one is coloured. The position of the coloured circle changes and is governed by a series of rules that alter without warning. Participants predict where 
the next coloured circle will appear by pointing to the location, having to quickly adapt to rule changes. The Pyramids and Palm Trees test (PPT; picture version; Howard \& Patterson, 1992) was used as a non-verbal measure of picture-semantic memory. Participants decide which of two pictures is associated with a target item and point to their chosen answer. The Test for Reception of Grammar (TROG-2; Bishop, 2003) measures sentence comprehension. The experimenter reads out sentences that increase in grammatical complexity and participants choose which of four pictures matches the stimulus sentence. The Boston Naming Test (BNT; Kaplan, Goodglass, \& Weintraub, 2001) measures lexical retrieval through picture naming.

Aphasic participants and matched HCs were not assessed on verbal IQ, as language impairment confounds measurement of intelligence/reasoning, nor on Block Design, due to comorbid motor deficits. The condensed test battery employed for aphasic participants and their controls therefore comprised WASI-II Matrix Reasoning, Brixton, PPT, BNT, and TROG-2.

\section{Procedure}

Participants with schizophrenia, FDRs and matched controls were tested in Newcastle University. Participants with aphasia and matched controls were tested in UCL, except one aphasic participant who was tested at home because of mobility problems. All clinical and cognitive assessments were completed by trained researchers. Each test was administered and scored according to its manual. All procedures were carried out in accordance with the Code of Ethics of the World Medical Association (Declaration of Helsinki).

\section{Statistical Analyses}

Group differences were tested using Analysis of (Co)Variance (AN(C)OVA), followed by post-hoc tests using Fisher's Least Significant Difference. Outliers were changed to the next highest/lowest value (Winsorized) to retain sample size and information about rank (Osborne, 2013). In the event of heterogeneity of variances, Welch's ANOVA and Games-Howell post-hoc tests were used and corrected degrees of freedom were reported. Some data were transformed to correct for violations of AN(C)OVA, and where transformation did not correct for violations, non-parametric tests were used (see appendix Table 4 for details). One-tailed Spearman's rank-order correlations were used to examine the relationship between $\mathrm{CD}$ score and cognitive performance.

For schizophrenia-aphasia comparisons, we compared the degree of impairment in each patient group in relation to controls by standardising performance scores based on means and standard deviations of respective age-matched HCs (z-scores). Composite verbal cognition scores were calculated by averaging TROG-2 and BNT z-scores, and composite non-verbal cognition scores were calculated by averaging Matrix Reasoning, Brixton and PPT z-scores. Pearson's correlations were used to examine the relationship between verbal and non-verbal cognitive performance. Tests were two-tailed, unless stated otherwise. Alpha was set at .05. For tests measuring similar constructs ( $\mathrm{VCl}$ and PRI), alpha was adjusted using the BonferroniHolm correction. SPSS for Windows (version 23; IBM Corp., 2013) was used.

\section{Results}

Table 1 displays demographics, clinical characteristics and mean cognitive scores for all groups. Table 2 displays results of ANOVA and multiple comparisons to test group differences. 
Table 1. Demographics, clinical characteristics and mean cognitive test scores for each group.

\begin{tabular}{|c|c|c|c|c|c|c|c|}
\hline & SZ & SZ+FTD & SZ-FTD & FDR & $\mathrm{HC}_{\mathrm{sz}}$ & Aphasia & $H C_{a p h}$ \\
\hline$N$ & 30 & 15 & 15 & 16 & 15 & 20 & 30 \\
\hline$\%$ Male & 77 & 87 & 67 & 50 & 47 & 80 & 30 \\
\hline$\%$ White British & 100 & 100 & 100 & 100 & 93 & - & - \\
\hline \% Right Handed & 87 & 80 & 93 & 88 & 100 & 100 & 93 \\
\hline Age in years & $43.9(12.8)$ & $49.9(14.6)$ & $38.0(7.3)$ & $44.9(12.6)$ & $45.1(13.0)$ & 63.7(10.7) & $70.2(7.0)$ \\
\hline Years of formal education & $13.9(3.8)$ & $14.8(3.6)$ & $12.9(4.0)$ & $16.7(4.0)$ & $16.3(3.6)$ & $13.9(2.2)$ & $14.3(2.0)$ \\
\hline Illness duration in months & $215.7(121.8)$ & $232.2(149.4)$ & 199.2(88.6) & - & - & $76.2(63.3)$ & - \\
\hline PANSS Conceptual Disorganisation Score & $3.4(2.0)$ & $5.2(0.9)$ & $1.5(0.6)$ & $1.3(0.6)$ & $1.0(0.0)$ & - & - \\
\hline PANSS Total Score & $101.3(22.1)$ & $114.4(19.4)$ & $88.3(16.3)$ & $52.7(20.4)$ & $40.1(5.8)$ & - & - \\
\hline NART Full IQ & 95.2(13.9) & $95.7(14.2)$ & $94.7(14.0)$ & 101.1(11.8) & $109.1(8.7)$ & - & - \\
\hline WASI-II Full Scale IQ-4 & $83.6(17.9)$ & $80.3(15.7)$ & $86.9(19.9)$ & 103.0(9.5) & $106.9(8.5)$ & - & - \\
\hline VCl & $81.8(15.8)$ & $78.9(13.3)$ & $84.7(18.0)$ & $92.3(11.7)$ & $102.3(7.8)$ & - & - \\
\hline
\end{tabular}




\begin{tabular}{|c|c|c|c|c|c|c|c|}
\hline PRI & $88.3(20.4)$ & $85.0(20.0)$ & $91.7(21.0)$ & $113.4(7.7)$ & 110.1(11.9) & - & - \\
\hline Matrix Reasoning & $43.5(13.3)$ & $39.8(12.9)$ & $47.3(13.0)$ & $62.4(7.8)$ & $57.5(9.3)$ & $49.4(10.1)$ & $56.0(6.1)$ \\
\hline TROG-2 Total Score & $15.2(4.3)$ & $13.7(5.1)$ & $16.6(3.0)$ & $17.4(2.7)$ & $18.4(1.6)$ & $12.0(5.0)$ & $19.0(0.9)$ \\
\hline BNT Overall Score & $52.9(5.3)$ & $53.1(5.0)$ & $52.7(5.8)$ & $55.9(2.7)$ & $56.5(2.5)$ & $40.8(15.4)$ & $57.3(2.4)$ \\
\hline Brixton Total Correct & $26.2(10.5)$ & $21.2(12.7)$ & $30.5(6.0)$ & $34.7(8.8)$ & $38.2(7.2)$ & $35.1(5.9)$ & $38.0(5.6)$ \\
\hline PPT Total Score & $48.8(3.4)$ & $47.7(4.3)$ & $49.8(1.7)$ & $50.8(0.4)$ & $50.9(0.9)$ & $49.65(3.2)$ & $50.5(1.5)$ \\
\hline
\end{tabular}

Data are reported as Mean (Standard Deviation). SZ = all participants with schizophrenia, SZ+FTD = schizophrenia with formal thought disorder, SZ-FTD =

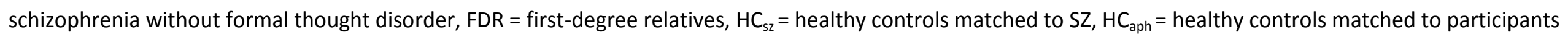

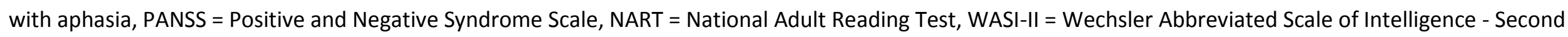
Edition, $\mathrm{VCl}=$ Verbal Comprehension Index, PRI = Perceptual Reasoning Index, TROG-2 = Test for Reception of Grammar, BNT = Boston Naming Test, PPT = Pyramids and Palm Trees. 
Table 2. Results of ANOVAs and multiple comparisons to test group differences in cognitive scores.

ANOVA with groups SZ, FDR, HC Multiple Comparisons ( $p$ )

\begin{tabular}{lccccccc}
\hline Cognitive Test & Statistic & DF & $p$ & ES & SZ vs FDR & SZ vs HC & FDR vs HC \\
\hline VCI & $F=16.99$ & $2,35.59$ & $<.001^{*}$ & $\omega^{2}=.34$ & $.036^{*}$ & $<.001^{*}$ & $.026^{*}$ \\
\hline PRI & $F=17.75$ & $2,34.84$ & $<.001^{*}$ & $\omega^{2}=.35$ & $<.001^{*}$ & $<.001^{*}$ & .637 \\
\hline TROG-2 & $F=6.22$ & 2,57 & $.004^{*}$ & $\eta_{p}^{2}=.18$ & $.060^{+}$ & $.001^{*}$ & .171 \\
\hline BNT & $F=5.27$ & $2,37.15$ & $.010^{*}$ & $\omega^{2}=.12$ & $.014^{*}$ & $.009^{*}$ & .910 \\
\hline Brixton & $F=9.18$ & 2,45 & $.001^{*}$ & $\eta_{p}^{2}=.29$ & $.014^{*}$ & $<.001^{*}$ & .254 \\
\hline PPT & $\chi^{2}=9.04$ & 2 & $.011^{*}$ & $\eta^{2}=.19$ & $.031^{*}$ & $.007^{*}$ & .737
\end{tabular}

ANOVA with groups SZ+FTD, SZ-FTD, HC

Multiple Comparisons $(p)$

\begin{tabular}{lccccccc}
\hline Cognitive Test & Statistic & DF & $p$ & ES & SZ+FTD vs SZ-FTD & SZ+FTD vs HC & SZ-FTD vs HC \\
\hline VCI & $F=1.83$ & 2,42 & $<.001^{*}$ & $\eta_{p}{ }^{2}=.36$ & .258 & $<.001^{*}$ & $.001^{*}$ \\
\hline PRI & $F=7.77$ & 2,42 & $.001^{*}$ & $\eta_{p}{ }^{2}=.27$ & .319 & $<.001^{*}$ & $.008^{*}$ \\
\hline TROG-2 & $F=7.85$ & 2,41 & $.001^{*}$ & $\eta_{p}{ }^{2}=.28$ & $.032^{*}$ & $<.001^{*}$ & .084 \\
\hline
\end{tabular}




\begin{tabular}{lccccccc}
\hline BNT & $F=4.66$ & $2,24.29$ & $.019^{*}$ & $\omega^{2}=.14$ & .984 & $.063^{\dagger}$ & .076 \\
\hline Brixton & $F=11.89$ & 2,34 & $<.001^{*}$ & $\eta_{\mathrm{p}}{ }^{2}=.41$ & $.056^{\dagger}$ & $<.001^{*}$ \\
\hline PPT & $\chi^{2}=8.06$ & 2 & $.018^{*}$ & $\eta^{2}=.18$ & .554 & $.014^{*}$
\end{tabular}

ANOVA with groups SZ+FTD, SZ-FTD, Aphasia

Multiple Comparisons $(p)$

\begin{tabular}{|c|c|c|c|c|c|c|c|}
\hline Cognitive Test (z-score) & Statistic & DF & $p$ & ES & Aphasia vs SZ+FTD & Aphasia vs SZ-FTD & SZ+FTD vs SZ-FTD \\
\hline Matrix Reasoning & $F=1.53$ & 2,46 & .227 & $\eta_{p}^{2}=.06$ & .120 & .975 & .149 \\
\hline TROG-2 & $F=14.86$ & 2,46 & $<.001^{*}$ & $\eta_{p}^{2}=.39$ & $.011^{*}$ & $<.001^{*}$ & .140 \\
\hline Brixton & $F=7.27$ & 2,41 & $.002 *$ & $\eta_{p}^{2}=.26$ & $<.001^{*}$ & .154 & $.031^{*}$ \\
\hline PPT & $F=5.24$ & $2,19.21$ & $.015^{*}$ & $\omega^{2}=.12$ & $.026^{*}$ & .230 & .244 \\
\hline
\end{tabular}

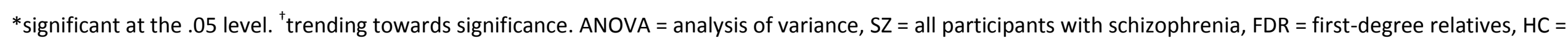

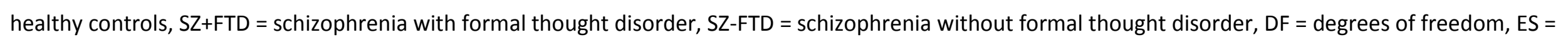
effect size, $\mathrm{VCI}=$ Verbal Comprehension Index, PRI = Perceptual Reasoning Index, TROG-2 = Test for Reception of Grammar, BNT = Boston Naming Test, PPT = Pyramids and Palm Trees. 
Note: Comparisons of SZ+FTD and SZ-FTD groups are presented twice with slightly different results taken from two different models: firstly, neuropsychological scores of the two groups were compared with that of controls, and in a second model, neuropsychological scores of the two groups were standardised against matched controls, then compared with standardised scores of participants with aphasia. 


\section{Cognitive Impairment in Schizophrenia}

To test $\mathrm{H} 1$, we compared cognitive performance of all patients with schizophrenia (SZ), FDRs and $\mathrm{HC}$. Groups differed on PANSS total score $\left(F(2,58)=65.24, p<.001, \mathrm{n}_{\mathrm{p}}{ }^{2}=.69\right)$ and $\mathrm{CD}$ score $(F(2,58)=17.46, p<.001$, $\eta_{\mathrm{p}}{ }^{2}=.38$ ). For both measures, $\mathrm{SZ}$ had higher scores than FDRs and $\mathrm{HC}$ (all $p s<.001$ ). There were no differences in age $\left(F(2,58)=8.74, p=.948, \eta_{\mathrm{p}}{ }^{2}=.002\right)$. Groups differed in years of education $\left(F(2,58)=3.66, p=.032, \eta_{\mathrm{p}}{ }^{2}=.11\right)$, pmlQ $\left(F(2,57)=6.39, p=.003, \eta_{p}{ }^{2}=.18\right)$, and current IQ $\left(F(2,58)=17.44, p<.001, \eta_{p}{ }^{2}=.38\right)$. SZ had fewer years of education than FDRs $(p=.020)$ and HC (trend level; $p=.050)$, lower pmIQ than HC $(p=.001)$, and lower current IQ than FDRs and $\mathrm{HC}$ (both $p s<.001)$.

Standard deviations show that SZ had more variance in cognitive test scores than FDRs and HC. PPT data were analysed with non-parametric tests (SZ mean rank=19.3, FDRs mean rank=30.0, and HC mean rank=31.9). ANOVA revealed that groups differed on every test. SZ had lower scores than FDRs and HC on all tasks, except TROG-2 where the difference between SZ and FDRs was at a trend level. FDRs scored lower than $\mathrm{HC}$ on VCl only. Since groups differed in years of education and $\mathrm{pmIQ}$, ANCOVA was also used, covarying for these variables (see appendix Table 5). In this case, the effect of group on TROG-2, PPT and BNT scores was no longer significant, and the SZ-FDR and FDR-HC differences in VCl were no longer significant.

\section{Cognitive Impairment in FTD}

To test $\mathrm{H2}$, we compared cognitive performance of SZ+FTD, SZ-FTD and HC. Groups differed on PANSS total score $\left(F(2,42)=94.41, p<.001, \eta_{p}^{2}=.82\right)$ : SZ+FTD scored higher than SZ-FTD and HC, and SZ-FTD scored higher than $\mathrm{HC}$ (all $p s<.001)$. Groups differed in age $\left(F(2,42)=3.69, p=.033, \eta_{\mathrm{p}}{ }^{2}=.15\right)$ : SZ+FTD were older than SZ-FTD $(p=.010)$. The model indicated no differences in years of education $\left(F(2,42)=2.99, p=.061, \eta_{p}{ }^{2}=.13\right)$, however, posthoc tests showed that SZ-FTD had fewer years of education than HC $(p=.019)$. Groups differed in pmIQ $\left(F(2,41)=6.07, p=.005, \eta_{p}{ }^{2}=.23\right)$ and current IQ $\left(F(2,42)=12.08, p<.001, \eta_{p}{ }^{2}=.37\right) ; S Z+F T D$ and SZ-FTD scored lower than HC (pmIQ $p=.006$ and $p=.003$, respectively; current IQ $p<.001$ and $p=.005$, respectively).

PPT data were analysed with non-parametric tests (SZ+FTD mean rank=13.29, SZ-FTD mean rank=19.08, and $\mathrm{HC}$ mean rank=25.65). ANOVA revealed that groups differed on all tests. SZ+FTD scored lower than SZ-FTD on TROG-2 and the difference in Brixton scores was at trend level. SZ+FTD scored lower than HC on all tests, except BNT, where if difference was at trend level. SZ-FTD scored lower than $\mathrm{HC}$ on VCI, PRI and Brixton. After covarying for pmIQ and years of education (ANCOVA), the effect of group for PPT and BNT scores was no longer significant, SZ-FTD only scored lower than HC on Brixton, and SZ+FTD scored lower than SZ-FTD on VCl and Brixton (see appendix Table 6).

CD score (FTD) was negatively correlated with scores on $\mathrm{VCl}(\rho(28)=-.35, p=.031), \operatorname{PRI}(\rho(28)=-.37, p=.023)$, Brixton $(\rho(22)=-.36, \mathrm{p}=.040)$, TROG-2 $(\rho(27)=-.39, \mathrm{p}=.019)$, and PPT $(\rho(23)=-.36, \mathrm{p}=.041)$, but not BNT $(\rho(23)=-.26$, $\mathrm{p}=.087$ ), in all participants with schizophrenia (pooled). $C D$ score did not correlate with any cognitive score in FDRs (see appendix Table 7).

\section{Comparison with Aphasia}

Independent samples t-tests revealed that the aphasia group scored lower than matched controls on Matrix Reasoning $(t(27.01)=-2.57, p=.016, d=0.78)$, TROG-2 $(t(22.81)=7.67, p<.001, d=2.38)$, BNT $(t(22.63)=6.14$, $p<.001, d=1.91)$, and Brixton $(t(45)=-2.31, p=.025, d=0.67)$, but not PPT $(t(48)=.79, p=.435, d=0.22)$. 
To test $\mathrm{H} 3$ and $\mathrm{H} 4$, we compared the cognitive performance of patients with SZ+FTD, SZ-FTD and aphasia. Table 3 and Figure 1 display mean cognitive z-scores for each group. ANOVA revealed that groups differed on all tests, except Matrix Reasoning. Participants with aphasia scored lower than SZ+FTD and SZ-FTD on TROG-2 and BNT. SZ+FTD scored lower than the aphasia group on Brixton and PPT, and scored lower than SZ-FTD on Brixton. When covarying for years of education (ANCOVA), groups also differed in Matrix Reasoning, with SZ+FTD scoring lower than aphasia and SZ-FTD participants, and SZ+FTD scored lower than SZ-FTD on TROG-2 and PPT (see appendix Table 8).

Table 3 displays composite verbal and non-verbal cognitive z-scores and Figure 2 illustrates the relationship between these in each group. Verbal and non-verbal performance correlated in SZ+FTD $(r(8)=.71$, $p=.022)$ and SZ-FTD $(r(11)=.84, p<.001)$, as well as when all participants with schizophrenia were pooled $(r(21)=.79, p<.001)$, but not in aphasia patients $(r(17)=.11, p=.667)$.

Table 3. Mean cognitive z-scores of participants with aphasia, SZ+FTD, and SZ-FTD.

\begin{tabular}{|c|c|c|c|c|c|c|}
\hline & \multicolumn{2}{|c|}{ Aphasia } & \multicolumn{2}{|r|}{ SZ+FTD } & \multicolumn{2}{|r|}{ SZ-FTD } \\
\hline & $N$ & Mean(SD) & $N$ & Mean(SD) & $N$ & Mean(SD) \\
\hline Verbal z-score & 19 & $-7.6(5.6)$ & 14 & $-2.3(2.3)$ & 15 & $-1.3(1.7)$ \\
\hline TROG-2 z-score & 20 & $-7.7(5.5)$ & 14 & $-2.9(3.2)$ & 15 & $-1.1(1.9)$ \\
\hline BNT z-score & 20 & $-7.0(6.5)$ & 15 & $-1.4(2.0)$ & 15 & $-1.5(2.3)$ \\
\hline Non-verbal z-score & 19 & $-0.7(1.2)$ & 11 & $-2.3(1.7)$ & 13 & $-1.0(1.1)$ \\
\hline Matrix Reasoning z-score & 19 & $-1.1(1.6)$ & 15 & $-1.9(1.4)$ & 15 & $-1.1(1.4)$ \\
\hline Brixton z-score & 20 & $-0.5(1.0)$ & 11 & $-2.4(1.8)$ & 13 & $-1.1(0.8)$ \\
\hline PPT z-score & 20 & $-0.6(2.1)$ & 12 & $-3.8(5.0)$ & 13 & $-1.2(2.0)$ \\
\hline
\end{tabular}

Data are reported as Mean (Standard Deviation). SZ+FTD = schizophrenia with formal thought disorder, SZ-FTD = schizophrenia without formal thought disorder, TROG-2 = Test for Reception of Grammar, BNT = Boston Naming Test, PPT = Pyramids and Palm Trees. Verbal z-score was calculated by averaging TROG-2 and BNT scores, and non-verbal z-score was calculated by averaging Matrix Reasoning, Brixton and PPT scores. 

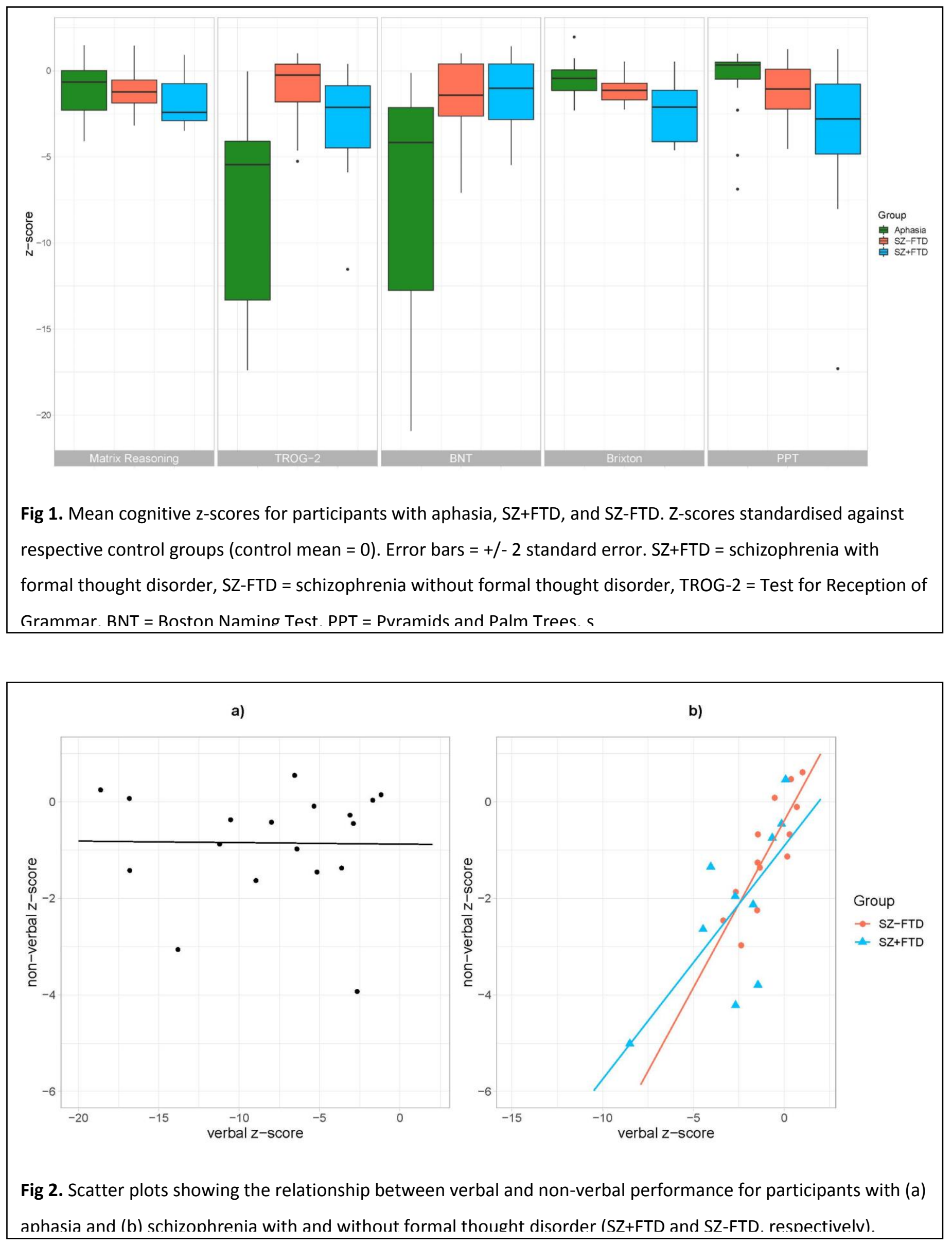


\section{Discussion}

This study compared verbal and non-verbal cognitive profiles of schizophrenia patients with and without FTD and in patients with aphasia. The latter comparisons are novel and allow evaluation of claims that language impairments play a causal role in the cognitive impairment seen in schizophrenia. Results showed that, as hypothesised and largely in keeping with previous research (Barrera et al., 2005; Goldberg et al., 1998; RodriguezFerrera et al., 2001; Schaefer et al., 2013; Stirling et al., 2006), schizophrenia was associated with impairment across all cognitive domains relative to controls. Deficits in EF and verbal and non-verbal intelligence (VCl and PRI) remained after accounting for pmIQ and years of education.

While both SZ+FTD and SZ-FTD showed deficits in VCI, PRI, and EF, there was a greater breadth of impairment in SZ+FTD, with additional deficits in picture-semantic memory and sentence comprehension, and more severe impairment in EF. The additional deficit in picture-semantic memory in SZ+FTD was inferred from a significant impairment (relative to controls) in SZ+FTD, whereas, in contrast with previous research (Doughty \& Done, 2009; Lawrence et al., 2007), we did not demonstrate an impact of SZ-FTD on the PPT task. When directly compared, the SZ+FTD and SZ-FTD groups did not differ in PPT score, thus further investigation is needed. Results of previous studies examining semantic performance, including naming ability, in schizophrenia and FTD are heterogeneous (Barrera et al., 2005; Bora et al., 2019; Landre et al., 1992; Leeson et al., 2006; Rodriguez-Ferrera et al., 2001), with IQ, test used, illness chronicity and control matching methodology contributing to heterogeneity (Doughty \& Done, 2009; Weickert et al., 2000). In our study, neither schizophrenia group showed deficits in naming and whilst the degree of FTD correlated with poor performance on almost all tests, BNT was the exception. Whilst previously identified contributors to variability need to be borne in mind, it is noteworthy that performance did not separate on the naming task, suggesting that the impairment associated with FTD may be specific to tasks requiring sentence comprehension. Overall, our hypothesis that FTD would be associated with more severe deficits across all tests was not supported.

Contrary to research suggesting cognitive impairment in FDRs of patients with schizophrenia (Bora et al., 2014), our FDR group displayed impairment only in verbal intelligence, and this difference disappeared when controlling for pmIQ and education.

As expected, the aphasia group displayed significant linguistic impairments, but also showed mild impairment on matrix reasoning and EF compared to neurotypical controls. There may be a number of reasons for this impairment, for example, loss of inner speech support might contribute to difficulties with matrix reasoning. However, naturally occurring brain lesions often disrupt the substrates of multiple cognitive mechanisms through direct damage or interruption of white matter tracts, leading to disconnection phenomena. Participants with aphasia showed more severe language deficits than both schizophrenia groups, consistent with research suggesting that schizophrenia and aphasia can be distinguished based on sentence comprehension and naming (Halpern \& McCartin-Clark, 1984; Taylor, 1999). However, despite more marked language impairment in aphasia, there was a dissociation with degree and breadth of non-verbal cognitive impairment. Verbal and nonverbal performance were strongly correlated in both schizophrenia groups but not in the aphasia group. These data suggest caution in assuming that cognitive impairment in schizophrenia is a consequence of language disruption. Instead, verbal and non-verbal impairment may be part of a generalised cognitive decline that impacts on multiple domains. However, communicative ability may remain a valid target in cognitive remediation strategies in schizophrenia.

There are a number of caveats with regard to these findings and preliminary conclusions. Since sample sizes were limited, we suggest replication to confirm these findings. Measuring degree of FTD with PANSS CD may 
also be problematic: FTD is associated with clinical severity of schizophrenia (Roche et al., 2015) and SZ+FTD showed higher PANSS total scores than SZ-FTD. It is therefore possible that the cognitive deficit in SZ+FTD, rather than reflecting a qualitative difference (which would suggest that SZ+FTD represents a distinct subgroup of schizophrenia), may be a quantitative difference, reflecting clinical severity of schizophrenia, rather than FTD, per se. Similarly, grouping participants based on FTD may itself be problematic. However, the negative correlations of CD score and scores on all cognitive tests (except BNT) support the results generated by group comparisons.

Our analysis of impairment was relational, i.e. we compared the deviation of each clinical group from its matched control group. The motivation for that was that participants with schizophrenia differed from participants with aphasia substantially in age, location, and test protocol. Thus, similar test scores across clinical groups can be interpreted as different degrees of impairment, dependent on the performance from their respective control groups. SZ+FTD and aphasic groups had similar scores on grammatical comprehension (TROG2; Table 1), but in relation to respective controls, the deviation in aphasia was significantly greater and the impairment was therefore judged as greater. This was caused by the aphasia-matched control group scoring higher and showing less variance than the schizophrenia-matched control group. This difference may be because of an accuracy increase associated with ageing, or because of methodological differences (e.g. location and experimenter) and sample characteristics (e.g. dialect) between the two control samples.

Since healthy controls were matched to the whole group of patients with schizophrenia, rather than the SZ+FTD group specifically, this should be borne in mind when comparing scores of the control group and SZ+FTD. Also, since groups differed on years of education and $\mathrm{pmIQ}$, results of ANCOVA controlling for these variables were also reported. However, pmIQ and education may not be independent of schizophrenia (e.g. schizophrenia symptoms interfering with educational attainment), and our a priori predictions did not include these variables, therefore we focused primarily on results generated by ANOVA. Likewise, since we tested verbal and non-verbal intelligence ( $\mathrm{VCl}$ and $\mathrm{PRI}$ ), we did not control for current IQ. Intelligence has been linked to cognitive and language performance (Landre et al., 1992; Rodriguez-Ferrera et al., 2001), and there may be a subgroup of schizophrenia patients with relatively spared IQ who do not show cognitive deficits (Weickert et al., 2000). A few participants with schizophrenia in our sample displayed relatively high $I Q$, therefore, these may have been 'cognitively preserved' patients whose performance could have skewed results. Other factors affecting language and cognition in schizophrenia that we did not control for include gender, symptomology, medication, age at admission and duration of illness (Amminger, Edwards, Brewer, Harrigan, \& McGorry, 2002; Landre et al., 1992).

The standardised tests employed in our investigation have advantages, such as easy reproducibility, but they are limited in the degree of specificity in identifying both verbal and non-verbal impairment. For example, in the case of the language probes, both picture naming and sentence-to-picture matching are proxy measures that subsume multiple sub-processes. Grammar, for instance, is a highly complex process that involves the ability to conceive or comprehend a complex message, select grammatical frames and integrate lexical complexity, and track sequences and structural dependencies within fractions of a second. More sensitive probes might reveal differences between language dysfunction in aphasia and schizophrenia and such differences might be critical mediators of performance in other cognitive domains. Future research should employ different methods to focus on these capacities and determine which are linked to general cognitive impairment. For example, studies should measure core functions of language, such as reference and propositional meaning (Zimmerer et al., 2017), and use implicit language measures, such as priming and reaction time tasks, in addition to explicit measures like those used here. 
It is also important to consider the interrelatedness of cognitive processes. While research suggests a generalised cognitive decline in schizophrenia (Schaefer et al., 2013), and our results suggest widespread cognitive impairment, it is possible that a specific cognitive impairment is responsible for poor performance in other cognitive tasks. For example, some suggest that observed working memory deficits could reflect deficits in inhibition (Eich, Nee, Insel, Malapani, \& Smith, 2014), and that executive dysfunction is responsible for poor performance of patients with schizophrenia in a processing speed task (Knowles et al., 2015). Future research into cognitive impairment in schizophrenia and aphasia would benefit from techniques from experimental cognitive psychology to more accurately measure cognitive deficits and examine their interaction.

Overall, these data reveal that, when using standardised tests, language impairment occurs in aphasia, in SZ+FTD and in SZ-FTD. Language was more impaired in aphasia than in schizophrenia, but another key difference between these groups lies in the specificity of the language performance, i.e. the degree to which it is integrated with impairment on other cognitive tasks, as well as the nature of this impairment. Aphasia and schizophrenia, particularly in those with FTD, is associated with impaired sentence understanding as measured by TROG-2, but while patients with aphasia show a more severe impairment with relatively preserved non-verbal performance, SZ+FTD participants have a broader pattern of cognitive impairment. Thus, the degree to which impaired language use is associated with other cognitive abilities varies across pathological populations to the point that the group most severely impaired in the language tests was the least impaired in non-verbal tests. In this way, whether a poor language score means that there is a more general cognitive impairment depends on the population. This may either be because language impairment is qualitatively different in schizophrenia compared to aphasia, being an expression of a fundamentally altered cognition in the former case but not the latter; or, in a more dualistic framework, it may be that language output can be disrupted because of direct damage to different systems. These results stress the need for more sophisticated linguistic profiling of language capacities in schizophrenia and FTD so as to understand the link to cognition and thought that they involve in this disorder. This insight would further illuminate the foundational question of the role of language in cognition.

\section{Acknowledgements}

This work was supported by the Arts and Humanities Research Council (grant AH/L004070/1); Northumberland Tyne and Wear NHS Foundation Trust (Research Capability Funding); and Ministerio de Economía y Competitividad (grant FFI 042177665-77665-4-16 to WH). The authors acknowledge Sarah Page and Kelsey Stoddart for their assistance in building the database.

\section{Disclosure of interest}

No potential conflict of interest was reported by the authors.

\section{Data availability statement}

The authors confirm that the data supporting the findings of this study are available in the supplementary materials. 


\section{Author Contributions}

This paper was conceived by WH, SW, RV and VZ. Test protocols were devised by INF, WH, HS, FD, DT, RV and VZ. MD, HS, DT and SW managed and carried out recruitment and assessment of participants with schizophrenia, FDRs and respective controls. RV and VZ recruited aphasic participants and respective controls, VZ assessed participants. DC cleaned and managed the data. BL analysed the data with support from PG, SW, VZ, RV and WH. BL wrote the first draft of the paper. BL, DC, DT, FD, INF, PG, RV, SW, VZ and WH contributed to drafts of the manuscript. The work was supported by a project grant to WH, DT and RV, for which WH is the PI.

\section{References}

American Psychiatric Association. (2000). Diagnostic and statistical manual of mental disorders (4th ed.). Washington, DC: Author.

Amminger, G. P., Edwards, J., Brewer, W. J., Harrigan, S., \& McGorry, P. D. (2002). Duration of untreated psychosis and cognitive deterioration in first-episode schizophrenia. Schizophrenia Research, 54(3), 223-230. https://doi.org/10.1016/S0920-9964(01)00278-X

Baldo, J. V., Dronkers, N. F., Wilkins, D., Ludy, C., Raskin, P., \& Kim, J. (2005). Is problem solving dependent on language? Brain and Language, 92(3), 240-250. https://doi.org/10.1016/j.bandl.2004.06.103

Baldo, J. V., Paulraj, S. R., Curran, B. C., \& Dronkers, N. F. (2015). Impaired reasoning and problem-solving in individuals with language impairment due to aphasia or language delay. Frontiers in Psychology, 6, 1523. https://doi.org/10.3389/fpsyg.2015.01523

Bambini, V., Arcara, G., Bechi, M., Buonocore, M., Cavallaro, R., \& Bosia, M. (2016). The communicative impairment as a core feature of schizophrenia: Frequency of pragmatic deficit, cognitive substrates, and relation with quality of life. Comprehensive Psychiatry, 71, 106-120. https://doi.org/10.1016/j.comppsych.2016.08.012

Barrera, A., McKenna, P. J., \& Berrios, G. E. (2005). Formal thought disorder in schizophrenia: an executive or a semantic deficit? Psychological Medicine, 35(1), 121-132. https://doi.org/10.1017/S003329170400279X

Bedi, G., Carrillo, F., Cecchi, G. A., Slezak, D. F., Sigman, M., Mota, N. B., ... Corcoran, C. M. (2015). Automated analysis of free speech predicts psychosis onset in high-risk youths. NPJ Schizophrenia, 1, 15030. https://doi.org/10.1038/npjschz.2015.30

Bishop, D. V. M. (2003). Test for reception of grammar: TROG-2. London, UK: PsychCorp, Pearson.

Bleuler, E. (1950). Dementia praecox of the group of schizophrenias (1911) (J.Zinkin, Trans.). New York: 
International Universities Press.

Bora, E., Lin, A., Wood, S. J., Yung, A. R., McGorry, P. D., \& Pantelis, C. (2014). Cognitive deficits in youth with familial and clinical high risk to psychosis: a systematic review and meta-analysis. Acta Psychiatrica Scandinavica, 130(1), 1-15. https://doi.org/10.1111/acps.12261

Bora, E., Yalincetin, B., Binnur, B., \& Alptekin, K. (2019). Neurocognitive and linguistic correlates of positive and negative formal thought disorder: A meta-analysis. Schizophrenia Research, (In Press). https://doi.org/10.1016/j.schres.2019.05.025

Bowie, C. R., \& Harvey, P. D. (2008). Communication abnormalities predict functional outcomes in chronic schizophrenia: Differential associations with social and adaptive functions. Schizophrenia Research, 103(13), 240-247. https://doi.org/10.1016/j.schres.2008.05.006

Burgess, P. W., \& Shallice, T. (1997). Hayling and Brixton Tests manual. Bury St. Edmunds, UK: Thames Valley Test Company.

Clark, A. (1998). Magic Words: How Language Augments Human Computation. In P. Carruthers \& J. Boucher (Eds.), Language and Thought: Interdisciplinary Themes (pp. 162-183). Cambridge: Cambridge University Press. https://doi.org/10.1.1.136.5159

Çokal, D., Sevilla, G., Jones, W. S., Zimmerer, V., Deamer, F., Douglas, M., ... Hinzen, W. (2018). The language profile of formal thought disorder. Npj Schizophrenia, 4(1), 1-8. https://doi.org/10.1038/s41537-018-0061-9

Condray, R., Steinhauer, S. R., van Kammen, D. P., \& Kasparek, A. (2002). The language system in schizophrenia: Effects of capacity and linguistic structure. Schizophrenia Bulletin, 28(3), 475-490. https://doi.org/10.1093/oxfordjournals.schbul.a006955

Crow, T. J. (1998). Nuclear schizophrenic symptoms as a window on the relationship between thought and speech. British Journal of Psychiatry, 173, 303-309. https://doi.org/10.1192/bjp.173.4.303

Crow, T. J. (2008). The "big bang" theory of the origin of psychosis and the faculty of language. Schizophrenia Research, 102(1-3), 31-52. https://doi.org/10.1016/j.schres.2008.03.010

DeLisi, L. E. (2001). Speech disorder in schizophrenia: review of the literature and exploration of its relation to the uniquely human capacity for language. Schizophrenia Bulletin, 27(3), 481-496. https://doi.org/10.1093/oxfordjournals.schbul.a006889

Dickerson, F., Boronow, J. J., Ringel, N., \& Parente, F. (1999). Social functioning and neurocognitive deficits in outpatients with schizophrenia: A 2-year follow-up. Schizophrenia Research, 37(1), 13-20. 
https://doi.org/10.1016/S0920-9964(98)00134-0

DiSimoni, F. G., Darley, F. L., \& Aronson, A. E. (1977). Patterns of dysfunction in schizophrenic patients on an aphasia test battery. Journal of Speech and Hearing Disorders, 42(4), 498-513.

https://doi.org/10.1044/jshd.4204.498

Doughty, O. J., \& Done, D. J. (2009). Is semantic memory impaired in schizophrenia? A systematic review and meta-analysis of 91 studies. Cognitive Neuropsychiatry, 14(6), 473-509.

https://doi.org/10.1080/13546800903073291

Eich, T. S., Nee, D. E., Insel, C., Malapani, C., \& Smith, E. E. (2014). Neural correlates of impaired cognitive control over working memory in schizophrenia. Biological Psychiatry, 76(2), 146-153.

https://doi.org/10.1016/j.biopsych.2013.09.032

Faber, R., Abrams, R., Taylor, M. A., Kasprison, A., Morris, C., \& Weisz, R. (1983). Comparison of SchizophrenicPatients with Formal Thought-Disorder and Neurologically Impaired Patients with Aphasia. American Journal of Psychiatry, 140(10), 1348-1351. https://doi.org/10.1176/ajp.140.10.1348

Fedorenko, E., \& Varley, R. (2016). Language and thought are not the same thing: Evidence from neuroimaging and neurological patients. Annals of the New York Academy of Sciences, 1369(1), 132-153. https://doi.org/10.1111/nyas.13046

Fineberg, S. K., Deutsch-Link, S., Ichinose, M., McGuinness, T., Bessette, A. J., Chung, C. K., \& Corlett, P. R. (2015). Word use in first-person accounts of schizophrenia. British Journal of Psychiatry, 206(1), 32-38. https://doi.org/10.1192/bjp.bp.113.140046

Fonseca, J., Ferreira, J. J., \& Martins, I. P. (2017). Cognitive performance in aphasia due to stroke: A systematic review. International Journal on Disability and Human Development, 16(2), 127-139. https://doi.org/10.1515/ijdhd-2016-0011

Fraser, W. I., King, K. M., Thomas, P., \& Kendell, R. E. (1986). The diagnosis of schizophrenia by language analysis. The British Journal of Psychiatry, 148(3), 275-278.

Goldberg, T. E., Aloia, M. S., Gourovitch, M. L., Missar, D., Pickar, D., \& Weinberger, D. R. (1998). Cognitive Substrates of Thought Disorder, I: The Semantic System. American Journal of Psychiatry, 155(12), 16711676. https://doi.org/10.1176/ajp.155.12.1671

Halpern, H., \& McCartin-Clark, M. (1984). Differential language characteristics in adult aphasic and schizophrenic subjects. Journal of Communication Disorders, 17(5), 289-307. https://doi.org/10.1016/00219924(84)90032-7 
Harrow, M., O’Connell, E. M., Herbener, E. S., Altman, A. M., Kaplan, K. J., \& Jobe, T. H. (2003). Disordered verbalizations in schizophrenia: A speech disturbance or thought disorder? Comprehensive Psychiatry, 44(5), 353-359. https://doi.org/10.1016/S0010-440X(03)00113-5

Hinzen, W., \& Rosselló, J. (2015). The linguistics of schizophrenia: thought disturbance as language pathology across positive symptoms. Frontiers in Psychology, 6, 971. https://doi.org/10.3389/fpsyg.2015.00971

Hinzen, W., Rosselló, J., \& McKenna, P. (2016). Can delusions be understood linguistically? Cognitive Neuropsychiatry, 21(4), 281-299. https://doi.org/10.1080/13546805.2016.1190703

Howard, D., \& Patterson, K. (1992). Pyramids and Palm Trees: A test of semantic access from pictures and words. Bury St. Edmunds, UK: Thames Valley Test Company.

IBM Corp. (2013). SPSS Statistics for Windows (version 23.0). Armonk, NY: IBM Corp.

Kaplan, E. F., Goodglass, H., \& Weintraub, S. (2001). The Boston Naming Test (BNT), second edition. Philadelphia: Lippincott Williams \& Wilkins.

Kay, S. R., Fiszbein, A., \& Opler, L. A. (1987). The Positive and Negative Syndrome Scale for Schizophrenia. Schizophrenia Bulletin, 13(2), 261-276. https://doi.org/10.1093/schbul/13.2.261

Kelter, S., Cohen, R., Engel, D., List, G., \& Strohner, H. (1977). The conceptual structure of aphasic and schizophrenic patients in a nonverbal sorting task. Journal of Psycholinguistic Research, 6(4), $279-303$. https://doi.org/10.1007/BF01068300

Kim, S.-J., Shim, J.-C., Kong, B.-G., Kang, J.-W., Moon, J.-J., Jeon, D.-W., ... Jung, D.-U. (2015). The Relationship between Language Ability and Cognitive Function in Patients with Schizophrenia. Clinical Psychopharmacology and Neuroscience, 13(3), 288-295. https://doi.org/10.9758/cpn.2015.13.3.288

Kircher, T. T. J., Liddle, P. F., Brammer, M. J., Williams, S. C. R., Murray, R. M., \& McGuire, P. K. (2001). Neural Correlates of Formal Thought Disorder in Schizophrenia. Archives of General Psychiatry, 58(8), 769-774. https://doi.org/10.1001/archpsyc.58.8.769

Kircher, T. T. J., Oh, T. M., Brammer, M. J., \& McGuire, P. K. (2005). Neural correlates of syntax production in schizophrenia. British Journal of Psychiatry, 186, 209-214. https://doi.org/10.1192/bjp.186.3.209

Kleist, K. (1914). Aphasia and Geisteskrankheit. Münchener Medizinische Wochenschrift, 61, 8-12.

Knowles, E. E. M., Weiser, M., David, A. S., Glahn, D. C., Davidson, M., \& Reichenberg, A. (2015). The Puzzle of Processing Speed, Memory, and Executive Function Impairments in Schizophrenia: Fitting the Pieces Together. Biological Psychiatry, 78(11), 786-793. https://doi.org/10.1016/j.biopsych.2015.01.018 
Kuperberg, G. R. (2010). Language in Schizophrenia Part 1: An Introduction. Linguistics and Language Compass, 4(8), 576-589. https://doi.org/10.1111/j.1749-818X.2010.00216.x

Landre, N. A., Taylor, M. A., \& Kearns, K. P. (1992). Language functioning in schizophrenic and aphasic patients. Neuropsychiatry, Neuropsychology and Behavioral Neurology, 5(1), 7-14.

Lawrence, V. A., Doughty, O., Al-Mousawi, A., Clegg, F., \& Done, D. J. (2007). Do overinclusion and distorted semantic category boundaries in schizophrenia arise from executive dysfunction? Schizophrenia Research, 94(1), 172-179. https://doi.org/10.1016/j.schres.2007.04.012

Leeson, V. C., Laws, K. R., \& McKenna, P. J. (2006). Formal thought disorder is characterised by impaired lexical access. Schizophrenia Research, 88(1-3), 161-168. https://doi.org/10.1016/j.schres.2006.07.005

Li, X., Branch, C. A., Ardekani, B. A., Bertisch, H., Hicks, C., \& DeLisi, L. E. (2007). fMRI study of language activation in schizophrenia, schizoaffective disorder and in individuals genetically at high risk. Schizophrenia Research, 96(1-3), 14-24. https://doi.org/10.1016/j.schres.2007.07.013

McKenna, P., \& Oh, T. (2005). Schizophrenic speech: making sense of bathroots and ponds that fall in doorways. Cambridge, UK: Cambridge University Press.

Mohamed, S., Rosenheck, R., Swartz, M., Stroup, S., Lieberman, J. A., \& Keefe, R. S. E. (2008). Relationship of Cognition and Psychopathy to Functional Impairment in Schizophrenia. American Journal of Psychiatry, 165, 978-987. https://doi.org/10.1176/appi.ajp.2008.07111713

Nelson, H. E., \& Willison, J. (1991). The National Adult Reading Test (NART): Test Manual. Windsor, UK: NFERNelson.

Oh, T. M., McCarthy, R. A., \& McKenna, P. J. (2002). Is there a schizophasia? A study applying the single case approach to formal thought disorder in schizophrenia. Neurocase, 8(3), 233-244.

https://doi.org/10.1093/neucas/8.3.233

Osborne, J. W. (2013). Best Practices in Data Cleaning: A Complete Guide to Everything You Need to Do Before and After Collecting Your Data Title. Los Angeles, CA: Sage Publications, Inc.

Palaniyappan, L., Crow, T. J., Hough, M., Voets, N. L., Liddle, P. F., James, S., ... James, A. C. (2013). Gyrification of Broca's region is anomalously lateralized at onset of schizophrenia in adolescence and regresses at 2 year follow-up. Schizophrenia Research, 147(1), 39-45. https://doi.org/10.1016/j.schres.2013.03.028

Reichenberg, A., \& Harvey, P. D. (2007). Neuropsychological impairments in schizophrenia: Integration of performance-based and brain imaging findings. Psychological Bulletin, 133(5), 833-858. 
https://doi.org/10.1037/0033-2909.133.5.833

Roche, E., Creed, L., Macmahon, D., Brennan, D., \& Clarke, M. (2015). The Epidemiology and Associated Phenomenology of Formal Thought Disorder: A Systematic Review. Schizophrenia Bulletin, 41(4), 951-962. https://doi.org/10.1093/schbul/sbu129

Rodriguez-Ferrera, S., McCarthy, R. A., \& McKenna, P. . J. (2001). Language in schizophrenia and its relationship to formal thought disorder. Psychological Medicine, 31(2), 197-205. https://doi.org/10.1017/\$003329170100321x

Sans-Sansa, B., McKenna, P. J., Canales-Rodríguez, E. J., Ortiz-Gil, J., López-Araquistain, L., Sarró, S., ... PomarolClotet, E. (2013). Association of formal thought disorder in schizophrenia with structural brain abnormalities in language-related cortical regions. Schizophrenia Research, 146(1-3), 308-313.

https://doi.org/10.1016/j.schres.2013.02.032

Schaefer, J., Giangrande, E., Weinberger, D. R., \& Dickinson, D. (2013). The global cognitive impairment in schizophrenia: Consistent over decades and around the world. Schizophrenia Research, 150(1), 42-50. https://doi.org/10.1016/j.schres.2013.07.009

Sevilla, G., Rosselló, J., Salvador, R., Sarró, S., López-Araquistain, L., Pomarol-Clotet, E., \& Hinzen, W. (2018). Deficits in nominal reference identify thought disordered speech in a narrative production task. PLOS ONE, 13(8), 1-15. https://doi.org/10.1371/journal.pone.0201545

Sheffield, J. M., Gold, J. M., Strauss, M. E., Carter, C. S., MacDonald, A. W., Ragland, J. D., ... Barch, D. M. (2014). Common and specific cognitive deficits in schizophrenia: relationships to function. Cognitive, Affective, \& Behavioral Neuroscience, 14(1), 161-174. https://doi.org/10.3758/s13415-013-0211-5

Stirling, J., Hellewell, J., Blakey, A., \& Deakin, W. (2006). Thought disorder in schizophrenia is associated with both executive dysfunction and circumscribed impairments in semantic function. Psychological Medicine, 36(4), 475. https://doi.org/10.1017/S0033291705006884

Sumiyoshi, C., Sumiyoshi, T., Nohara, S., Yamashita, I., Matsui, M., Kurachi, M., \& Niwa, S. (2005). Disorganization of semantic memory underlies alogia in schizophrenia: An analysis of verbal fluency performance in Japanese subjects. Schizophrenia Research, 74(1), 91-100. https://doi.org/10.1016/j.schres.2004.05.011

Tan, E. J., Thomas, N., \& Rossell, S. L. (2014). Speech disturbances and quality of life in schizophrenia: Differential impacts on functioning and life satisfaction. Comprehensive Psychiatry, 55(3), 693-698. https://doi.org/10.1016/j.comppsych.2013.10.016

Tan, E. J., Yelland, G. W., \& Rossell, S. L. (2016). Characterising receptive language processing in schizophrenia 
using word and sentence tasks. Cognitive Neuropsychiatry, 21(1), 14-31.

https://doi.org/10.1080/13546805.2015.1121866

Taylor, M. A. (1999). The fundamentals of clinical neuropsychiatry. New York, NY: Oxford University Press.

Titone, D., Libben, M., Niman, M., Ranbom, L., \& Levy, D. L. (2007). Conceptual combination in schizophrenia: Contrasting property and relational interpretations. Journal of Neurolinguistics, 20(2), 92-110. https://doi.org/10.1016/j.jneuroling.2006.06.002

Varley, R. (2014). Reason without much language. Language Sciences, 48, 232-244. https://doi.org/10.1016/j.langsci.2014.06.012

Wechsler, D. (2011). Wechsler Abbreviated Scale of Intelligence - Second Edition (WASI-II). San Antonio, TX: NCS Pearson.

Weickert, T. W., Goldberg, T. E., Gold, J. M., Bigelow, L. B., Egan, M. F., \& Weinberger, D. R. (2000). Cognitive impairments in patients with schizophrenia displaying preserved and compromised intellect. Archives of General Psychiatry, 57(9), 907-913. https://doi.org/10.1001/archpsyc.57.9.907

Willems, R. M., Benn, Y., Hagoort, P., Toni, I., \& Varley, R. (2011). Communicating without a functioning language system: Implications for the role of language in mentalizing. Neuropsychologia, 49(11), 3130-3135. https://doi.org/10.1016/j.neuropsychologia.2011.07.023

Zimmerer, V. C., Watson, S., Turkington, D., Ferrier, I. N., \& Hinzen, W. (2017). Deictic and propositional meaning New perspectives on language in Schizophrenia. Frontiers in Psychiatry, 8(FEB), 17. https://doi.org/10.3389/fpsyt.2017.00017 


\section{Appendix}

Table 4. Details of data transformations and statistical models used for each stage of the analysis.

\begin{tabular}{|c|c|c|c|}
\hline Data & Statistical model used & Data transformed & Reason \\
\hline \multicolumn{4}{|c|}{ H1) Comparison of cognitive performance of pooled SZ group, FDRs and matched controls } \\
\hline WASI-II VCI & $\begin{array}{l}\text { Welch's ANOVA and Games-Howell post-hoc } \\
\text { tests }\end{array}$ & N/A & Variances not homogeneous \\
\hline WASI-II PRI & $\begin{array}{l}\text { Welch's ANOVA and Games-Howell post-hoc } \\
\text { tests }\end{array}$ & N/A & Variances not homogeneous \\
\hline TROG-2 score & $\begin{array}{l}\text { ANOVA and pairwise comparisons with Fisher's } \\
\text { Least Significant Difference }\end{array}$ & Reflect and log transform & Negatively skewed, outliers \\
\hline BNT score & $\begin{array}{l}\text { ANOVA and pairwise comparisons with Fisher's } \\
\text { Least Significant Difference }\end{array}$ & Winsorization of outlier(s) & Outlier \\
\hline Brixton score & $\begin{array}{l}\text { ANOVA and pairwise comparisons with Fisher's } \\
\text { Least Significant Difference }\end{array}$ & Winsorization of outlier(s) & Negatively skewed, outliers \\
\hline PPT score & $\begin{array}{l}\text { Kruskal-Wallis } \mathrm{H} \text { test and Dunn's pairwise } \\
\text { comparisons }\end{array}$ & N/A & $\begin{array}{l}\text { Negatively skewed, outliers } \\
\text { (transformation did not correct violations } \\
\text { of assumptions) }\end{array}$ \\
\hline
\end{tabular}




\begin{tabular}{|c|c|c|c|}
\hline WASI-II VCI & $\begin{array}{l}\text { ANCOVA and pairwise comparisons with } \\
\text { Fisher's Least Significant Difference }\end{array}$ & $\begin{array}{l}\text { Comparison ANCOVA with outlier } \\
\text { removed - result the same }\end{array}$ & Outlier \\
\hline WASI-II PRI & $\begin{array}{l}\text { ANCOVA and pairwise comparisons with } \\
\text { Fisher's Least Significant Difference }\end{array}$ & Square transform & Heteroscedastic \\
\hline TROG-2 score & $\begin{array}{l}\text { ANCOVA and pairwise comparisons with } \\
\text { Fisher's Least Significant Difference }\end{array}$ & Reflect and log transform & $\begin{array}{l}\text { Negatively skewed, outliers, } \\
\text { heteroscedastic }\end{array}$ \\
\hline BNT score & $\begin{array}{l}\text { ANCOVA and pairwise comparisons with } \\
\text { Fisher's Least Significant Difference }\end{array}$ & Reflect and log transform & Outliers, heteroscedastic \\
\hline Brixton score & $\begin{array}{l}\text { ANCOVA and pairwise comparisons with } \\
\text { Fisher's Least Significant Difference }\end{array}$ & Reflect and square-root transform & Negatively skewed \\
\hline PPT score & $\begin{array}{l}\text { ANCOVA and pairwise comparisons with } \\
\text { Fisher's Least Significant Difference }\end{array}$ & Reflect and square-root transform & $\begin{array}{l}\text { Negatively skewed, outliers, } \\
\text { heteroscedastic }\end{array}$ \\
\hline \multicolumn{4}{|c|}{ H2) Comparison of cognitive performance of SZ+FTD, SZ-FTD and matched controls } \\
\hline WASI-II VCI & $\begin{array}{l}\text { ANOVA and pairwise comparisons with Fisher's } \\
\text { Least Significant Difference }\end{array}$ & N/A & N/A \\
\hline WASI-II PRI & $\begin{array}{l}\text { ANOVA and pairwise comparisons with Fisher's } \\
\text { Least Significant Difference }\end{array}$ & Winsorization of outlier(s) & Outlier \\
\hline TROG-2 score & $\begin{array}{l}\text { ANOVA and pairwise comparisons with Fisher's } \\
\text { Least Significant Difference }\end{array}$ & Reflect and square-root transform & $\begin{array}{l}\text { Negatively skewed, outliers, variances not } \\
\text { homogeneous }\end{array}$ \\
\hline BNT score & $\begin{array}{l}\text { Welch's ANOVA and Games-Howell post-hoc } \\
\text { tests }\end{array}$ & N/A & Variances not homogeneous \\
\hline
\end{tabular}




\begin{tabular}{|c|c|c|c|}
\hline Brixton score & $\begin{array}{l}\text { ANOVA and pairwise comparisons with Fisher's } \\
\text { Least Significant Difference }\end{array}$ & Reflect and square-root transform & $\begin{array}{l}\text { Negatively skewed, outliers, variances not } \\
\text { homogeneous }\end{array}$ \\
\hline PPT score & $\begin{array}{l}\text { Kruskal-Wallis } \mathrm{H} \text { test and Dunn's pairwise } \\
\text { comparisons }\end{array}$ & N/A & $\begin{array}{l}\text { Negatively skewed, outliers, variances not } \\
\text { homogeneous (transformation did not } \\
\text { correct violations of assumptions) }\end{array}$ \\
\hline \multicolumn{4}{|c|}{ H2) Comparison of cognitive performance of SZ+FTD, SZ-FTD and matched controls, controlling for years of education and pmIQ } \\
\hline WASI-II VCI & $\begin{array}{l}\text { ANCOVA and pairwise comparisons with } \\
\text { Fisher's Least Significant Difference }\end{array}$ & N/A & N/A \\
\hline WASI-II PRI & $\begin{array}{l}\text { ANCOVA and pairwise comparisons with } \\
\text { Fisher's Least Significant Difference }\end{array}$ & N/A & N/A \\
\hline TROG-2 score & $\begin{array}{l}\text { ANCOVA and pairwise comparisons with } \\
\text { Fisher's Least Significant Difference }\end{array}$ & Reflect and square-root transform & $\begin{array}{l}\text { Negatively skewed, outliers, } \\
\text { heteroscedastic }\end{array}$ \\
\hline BNT score & $\begin{array}{l}\text { ANCOVA and pairwise comparisons with } \\
\text { Fisher's Least Significant Difference }\end{array}$ & Reflect and square-root transform & Negatively skewed, heteroscedastic \\
\hline Brixton score & $\begin{array}{l}\text { ANCOVA and pairwise comparisons with } \\
\text { Fisher's Least Significant Difference }\end{array}$ & Reflect and square-root transformation & Negatively skewed, heteroscedastic \\
\hline PPT score & $\begin{array}{l}\text { ANCOVA and pairwise comparisons with } \\
\text { Fisher's Least Significant Difference }\end{array}$ & Reflect and inverse transform & $\begin{array}{l}\text { Negatively skewed, heteroscedastic, } \\
\text { outliers }\end{array}$ \\
\hline \multicolumn{4}{|c|}{ H2) Correlation of Conceptual Disorganisation (CD) score and cognitive performance in SZ } \\
\hline WASI-II VCI & Spearman's rank-order correlation (one-tailed) & N/A & Data skewed \\
\hline
\end{tabular}




\begin{tabular}{|c|c|c|c|}
\hline WASI-II PRI & Spearman's rank-order correlation (one-tailed) & N/A & Data skewed \\
\hline TROG-2 score & Spearman's rank-order correlation (one-tailed) & $\mathrm{N} / \mathrm{A}$ & Data skewed \\
\hline BNT score & Spearman's rank-order correlation (one-tailed) & $\mathrm{N} / \mathrm{A}$ & Data skewed \\
\hline Brixton score & Spearman's rank-order correlation (one-tailed) & $\mathrm{N} / \mathrm{A}$ & Data skewed \\
\hline PPT score & Spearman's rank-order correlation (one-tailed) & $\mathrm{N} / \mathrm{A}$ & Data skewed \\
\hline
\end{tabular}

H3) Comparison of cognitive performance of aphasia patients and matched controls

\begin{tabular}{|c|c|c|c|}
\hline $\begin{array}{l}\text { WASI-II Matrix } \\
\text { Reasoning }\end{array}$ & $\begin{array}{l}\text { Independent t-test (equal variances not } \\
\text { assumed) }\end{array}$ & $\mathrm{N} / \mathrm{A}$ & Variances not homogeneous \\
\hline TROG-2 score & $\begin{array}{l}\text { Independent t-test (equal variances not } \\
\text { assumed) }\end{array}$ & Reflect and square-root transform & $\begin{array}{l}\text { Data skewed, outliers, variances not } \\
\text { homogeneous }\end{array}$ \\
\hline BNT score & $\begin{array}{l}\text { Independent t-test (equal variances not } \\
\text { assumed) }\end{array}$ & Reflect and square-root transform & $\begin{array}{l}\text { Data skewed, outliers, variances not } \\
\text { homogeneous }\end{array}$ \\
\hline Brixton score & Independent t-test & Winsorization of outlier(s) & Outlier \\
\hline PPT score & Independent t-test & Reflect and log transform & $\begin{array}{l}\text { Data skewed, outliers, variances not } \\
\text { homogeneous }\end{array}$ \\
\hline \multicolumn{4}{|c|}{ H3) Comparison of cognitive z-scores of aphasia patients, SZ+FTD and SZ-FTD } \\
\hline $\begin{array}{l}\text { WASI-II Matrix } \\
\text { Reasoning }\end{array}$ & $\begin{array}{l}\text { ANOVA and pairwise comparisons with Fisher's } \\
\text { Least Significant Difference }\end{array}$ & N/A & N/A \\
\hline
\end{tabular}




\begin{tabular}{|c|c|c|c|}
\hline TROG-2 score & $\begin{array}{l}\text { ANOVA and pairwise comparisons with Fisher's } \\
\text { Least Significant Difference }\end{array}$ & Winsorization of outlier(s) & Outliers \\
\hline BNT score & $\begin{array}{l}\text { ANOVA and pairwise comparisons with Fisher's } \\
\text { Least Significant Difference }\end{array}$ & Reflect and log transform & $\begin{array}{l}\text { Negatively skewed, variances not } \\
\text { homogeneous }\end{array}$ \\
\hline Brixton score & $\begin{array}{l}\text { ANOVA and pairwise comparisons with Fisher's } \\
\text { Least Significant Difference }\end{array}$ & Reflect and square-root transform & Variances not homogeneous \\
\hline PPT score & $\begin{array}{l}\text { Welch's ANOVA and Games-Howell post-hoc } \\
\text { tests }\end{array}$ & Winsorization of outlier(s) & $\begin{array}{l}\text { Negatively skewed, outliers variances not } \\
\text { homogeneous }\end{array}$ \\
\hline
\end{tabular}

H3) Comparison of cognitive z-scores of aphasia patients, SZ+FTD and SZ-FTD, controlling for years of education

\begin{tabular}{|c|c|c|c|}
\hline $\begin{array}{l}\text { WASI-II Matrix } \\
\text { Reasoning }\end{array}$ & $\begin{array}{l}\text { ANCOVA and pairwise comparisons with } \\
\text { Fisher's Least Significant Difference }\end{array}$ & N/A & N/A \\
\hline TROG-2 score & $\begin{array}{l}\text { ANCOVA and pairwise comparisons with } \\
\text { Fisher's Least Significant Difference }\end{array}$ & Reflect and log transform & Negatively skewed, heteroscedastic \\
\hline BNT score & $\begin{array}{l}\text { ANCOVA and pairwise comparisons with } \\
\text { Fisher's Least Significant Difference }\end{array}$ & Reflect and log transform & Negatively skewed, heteroscedastic \\
\hline Brixton score & $\begin{array}{l}\text { ANCOVA and pairwise comparisons with } \\
\text { Fisher's Least Significant Difference }\end{array}$ & Reflect and square-root transform & Variances not homogeneous \\
\hline PPT score & $\begin{array}{l}\text { ANCOVA and pairwise comparisons with } \\
\text { Fisher's Least Significant Difference }\end{array}$ & Reflect and square-root transform & $\begin{array}{l}\text { Negatively skewed, heteroscedastic, } \\
\text { outliers }\end{array}$ \\
\hline
\end{tabular}

H4) Correlation of (composite) verbal and non-verbal performance of aphasia patients, SZ+FTD and SZ-FTD 


\begin{tabular}{|c|c|c|c|}
\hline Verbal performance & Pearson's correlation & N/A & $\mathrm{N} / \mathrm{A}$ \\
\hline Non-verbal performance & Pearson's correlation & $\mathrm{N} / \mathrm{A}$ & $\mathrm{N} / \mathrm{A}$ \\
\hline
\end{tabular}

ANOVA = analysis of variance, ANCOVA = analysis of covariance SZ = all participants with schizophrenia (pooled), FDR = first-degree relatives, SZ+FTD = schizophrenia with formal thought disorder, SZ-FTD = schizophrenia without formal thought disorder, WASI-II = Wechsler Abbreviated Scale of Intelligence -

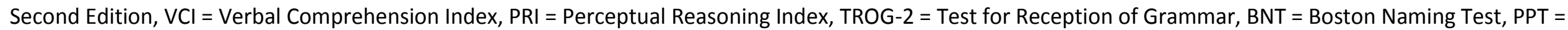
Pyramids and Palm Trees. 
Table 5. Results of ANCOVA and multiple comparisons to test differences between SZ, FDR and HC groups on each cognitive test, controlling for NART Full IQ and years of formal education.

\section{Cognitive Test}

ANCOVA

Multiple Comparisons (p)

$$
\begin{array}{lllllll}
F & \mathrm{DF} & \boldsymbol{p} & \mathrm{n}_{\mathrm{p}}{ }^{2} & \mathrm{SZ}<\mathrm{FDR} & \mathrm{SZ}<\mathrm{HC} & \mathrm{FDR}<\mathrm{HC}
\end{array}
$$

\begin{tabular}{|c|c|c|c|c|c|c|c|c|}
\hline \multirow[t]{4}{*}{ WASI-II VCI } & Model & 13.15 & 4,55 & $<.001^{*}$ & .49 & \multirow[t]{4}{*}{.113} & \multirow[t]{4}{*}{$.001^{*}$} & \multirow[t]{4}{*}{.086} \\
\hline & Group & 5.76 & 2,55 & $.005^{*}$ & .17 & & & \\
\hline & Education & 3.89 & 1,55 & $.054^{+}$ & .07 & & & \\
\hline & NART & 4.36 & 1,55 & $.041^{*}$ & .07 & & & \\
\hline \multirow[t]{4}{*}{ WASI-II PRI } & Model & 13.24 & 4,55 & $<.001^{*}$ & .49 & \multirow[t]{4}{*}{$<.001^{*}$} & \multirow[t]{4}{*}{$.019 *$} & \multirow[t]{4}{*}{.253} \\
\hline & Group & 8.30 & 2,55 & $<.001^{*}$ & .23 & & & \\
\hline & Education & 2.51 & 1,55 & .119 & .04 & & & \\
\hline & NART & 4.67 & 1,55 & $.035^{*}$ & .08 & & & \\
\hline TROG-2 Total & Model & 4.88 & 4,54 & $.002 *$ & .27 & \multirow[t]{4}{*}{.235} & \multirow[t]{4}{*}{$.065^{+}$} & \multirow[t]{4}{*}{.462} \\
\hline \multirow[t]{3}{*}{ Score } & Group & 1.90 & 2,54 & .160 & .07 & & & \\
\hline & Education & $<.001$ & 1,54 & .969 & $<.001$ & & & \\
\hline & NART & 4.68 & 1,54 & $.035^{*}$ & .08 & & & \\
\hline BNT Overall & Model & 14.27 & 4,55 & $<.001^{*}$ & .51 & \multirow[t]{4}{*}{.491} & \multirow[t]{4}{*}{.847} & \multirow[t]{4}{*}{.679} \\
\hline \multirow[t]{3}{*}{ Score } & Group & 0.24 & 2,55 & .785 & .01 & & & \\
\hline & Education & 1.34 & 1,55 & .252 & .02 & & & \\
\hline & NART & 21.18 & 1,55 & $<.001^{*}$ & .28 & & & \\
\hline Brixton Total & Model & 5.27 & 4,42 & $.002 *$ & .33 & \multirow[t]{3}{*}{$.046^{*}$} & \multirow[t]{3}{*}{$.001^{*}$} & \multirow[t]{3}{*}{.213} \\
\hline \multirow[t]{2}{*}{ Correct } & Group & 6.17 & 2,42 & $.004^{*}$ & .23 & & & \\
\hline & Education & 4.44 & 1,42 & $.041 *$ & .10 & & & \\
\hline
\end{tabular}




\begin{tabular}{|c|c|c|c|c|c|c|c|c|}
\hline & NART & 1.10 & 1,42 & .300 & .03 & & & \\
\hline PPT Total & Model & 3.54 & 4,43 & $.014 *$ & .25 & .142 & $.052^{+}$ & .676 \\
\hline \multirow[t]{3}{*}{ Score } & Group & 2.30 & 2,43 & .112 & .10 & & & \\
\hline & Education & 2.00 & 1,43 & .164 & .04 & & & \\
\hline & NART & 0.15 & 1,43 & .703 & $<.001$ & & & \\
\hline
\end{tabular}

*significant at the .05 level. ${ }^{\dagger}$ trending towards significance. ANCOVA = analysis of covariance, DF = degrees of freedom, NART = National Adult Reading Test, SZ = all participants with schizophrenia, FDR = first-degree relatives, $\mathrm{HC}=$ healthy controls, $\mathrm{WASI}-\mathrm{II}=$ Wechsler Abbreviated Scale of Intelligence - Second Edition, $\mathrm{VCI}=$ Verbal Comprehension Index, PRI = Perceptual Reasoning Index, TROG-2 = Test for Reception of Grammar, BNT = Boston Naming Test, PPT = Pyramids and Palm Trees. 
Table 6. Results of ANCOVA and multiple comparisons to test differences between SZ+FTD, SZ-FTD and HC groups on each cognitive test, controlling for NART Full IQ and years of formal education.

\begin{tabular}{|c|c|c|c|c|c|c|c|c|}
\hline \multirow[t]{3}{*}{ Cognitive Test } & \multicolumn{5}{|c|}{ ANCOVA } & \multicolumn{3}{|c|}{ Multiple Comparisons $(p)$} \\
\hline & & $\boldsymbol{F}$ & DF & $p$ & $\eta_{p}^{2}$ & SZ+FTD $<$ & SZ+FTD $<$ & SZ-FTD < \\
\hline & & & & & & SZ-FTD & $\mathrm{HC}$ & $\mathrm{HC}$ \\
\hline \multirow[t]{4}{*}{ WASI-II VCI } & Model & 11.98 & 4,39 & $<.001^{*}$ & .55 & $.047^{*}$ & $<.001^{*}$ & $.059^{+}$ \\
\hline & Group & 7.43 & 2,39 & $.002^{*}$ & .28 & & & \\
\hline & Education & 5.14 & 1,39 & $.029 *$ & .12 & & & \\
\hline & NART & 1.57 & 1,39 & .217 & .04 & & & \\
\hline \multirow[t]{4}{*}{ WASI-II PRI } & Model & 8.42 & 4,39 & $<.001^{*}$ & .46 & .123 & $.012 *$ & .253 \\
\hline & Group & 3.51 & 2,39 & $.040 *$ & .15 & & & \\
\hline & Education & 2.53 & 1,39 & .120 & .06 & & & \\
\hline & NART & 3.09 & 1,39 & .087 & .15 & & & \\
\hline \multirow[t]{4}{*}{ TROG-2 Total Score } & Model & 4.66 & 4,38 & $.004^{*}$ & .33 & $.052^{+}$ & $.017^{*}$ & .494 \\
\hline & Group & 3.46 & 2,38 & $.042^{*}$ & .15 & & & \\
\hline & Education & 0.02 & 1,38 & .879 & .001 & & & \\
\hline & NART & 2.17 & 1,38 & .149 & .05 & & & \\
\hline \multirow[t]{4}{*}{ BNT Overall Score } & Model & 8.76 & 4,39 & $<.001^{*}$ & .47 & .585 & .903 & .528 \\
\hline & Group & 0.12 & 2,39 & .889 & .01 & & & \\
\hline & Education & 0.34 & 1,39 & .556 & .01 & & & \\
\hline & NART & 13.49 & 1,39 & $.001 *$ & .26 & & & \\
\hline \multirow[t]{2}{*}{ Brixton Total Correct } & Model & 6.61 & 4,31 & $.001^{*}$ & .46 & $.017^{*}$ & $<.001^{*}$ & $.017^{*}$ \\
\hline & Group & 10.21 & 2,31 & $<.001^{*}$ & .40 & & & \\
\hline
\end{tabular}




\begin{tabular}{|c|c|c|c|c|c|c|c|c|}
\hline & Education & 3.15 & 1,31 & .086 & .09 & & & \\
\hline & NART & 1.09 & 1,31 & .304 & .03 & & & \\
\hline \multirow[t]{4}{*}{ PPT Total Score } & Model & 4.63 & 4,32 & $.005 *$ & .37 & \multirow[t]{4}{*}{.093} & \multirow[t]{4}{*}{.807} & \multirow[t]{4}{*}{.178} \\
\hline & Group & 1.64 & 2,32 & .209 & .09 & & & \\
\hline & Education & 3.70 & 1,32 & $.063^{+}$ & .10 & & & \\
\hline & NART & 1.18 & 1,32 & 286 & .04 & & & \\
\hline
\end{tabular}

*significant at the .05 level. ${ }^{\dagger}$ trending towards significance. ANCOVA = analysis of covariance, DF = degrees of freedom, NART = National Adult Reading Test, SZ+FTD = schizophrenia with formal thought disorder, SZFTD = schizophrenia without formal thought disorder, $\mathrm{HC}=$ healthy controls, WASI-II = Wechsler Abbreviated Scale of Intelligence - Second Edition, $\mathrm{VCI}=$ Verbal Comprehension Index, PRI = Perceptual Reasoning Index, TROG-2 = Test for Reception of Grammar, BNT = Boston Naming Test, PPT = Pyramids and Palm Trees.

Table 7. Results of one-tailed Spearman's correlations of Conceptual Disorganisation score and neuropsychological scores in the first degree relatives of patients with schizophrenia.

\begin{tabular}{ll}
\hline Cognitive Test & Spearman's correlation \\
\hline WASI-II VCI & $\rho(14)=-.190, p=.241$ \\
\hline WASI-II PRI & $\rho(14)=.222, p=.204$ \\
\hline TROG-2 Total Score & $\rho(14)=-.030, p=.455$ \\
\hline BNT Overall Score & $\rho(14)=-.165, p=.271$ \\
\hline Brixton Total Correct & $\rho(9)=-.225, p=.253$ \\
\hline PPT Total Score & $\rho(9)=-.190, p=.288$
\end{tabular}

WASI-II = Wechsler Abbreviated Scale of Intelligence - Second Edition, $\mathrm{VCI}=$ Verbal Comprehension Index PRI = Perceptual Reasoning Index, TROG-2 = Test for Reception of Grammar, BNT = Boston Naming Test, PPT $=$ Pyramids and Palm Trees . 
Table 8. Results of ANCOVA to test group differences in cognitive z-scores between participants with aphasia, SZ+FTD and SZ-FTD, controlling for years of formal education.

\begin{tabular}{|c|c|c|c|c|c|c|c|c|}
\hline \multirow[t]{2}{*}{ Cognitive Test } & \multicolumn{5}{|c|}{ ANCOVA } & \multicolumn{3}{|c|}{ Multiple Comparisons $(p)$} \\
\hline & & $\boldsymbol{F}$ & DF & $p$ & $\eta_{p}^{2}$ & $\begin{array}{l}\text { Aphasia vs } \\
\text { SZ+FTD }\end{array}$ & $\begin{array}{l}\text { Aphasia vs } \\
\text { SZ-FTD }\end{array}$ & $\begin{array}{l}\text { SZ+FTD vs } \\
\text { SZ-FTD }\end{array}$ \\
\hline \multirow{3}{*}{$\begin{array}{l}\text { Matrix Reasoning } \\
\text { z-score }\end{array}$} & Model & 4.85 & 3,45 & $.005^{*}$ & .24 & $.037^{*}$ & .743 & $.026 *$ \\
\hline & Group & 3.23 & 2,45 & $.049 *$ & .13 & & & \\
\hline & Education & 10.84 & 1,45 & $.002 *$ & .13 & & & \\
\hline \multirow[t]{3}{*}{ TROG-2 z-score } & Model & 10.72 & 3,45 & $<.001^{*}$ & .42 & $.004^{*}$ & $<.001^{*}$ & $.034^{*}$ \\
\hline & Group & 15.69 & 2,45 & $<.001^{*}$ & .41 & & & \\
\hline & Education & 1.88 & 1,45 & .178 & .04 & & & \\
\hline \multirow[t]{3}{*}{ BNT z-score } & Model & 8.25 & 3,46 & $.001^{*}$ & .35 & $.001^{*}$ & $<.001^{*}$ & .718 \\
\hline & Group & 10.62 & 2,46 & $<.001^{*}$ & .32 & & & \\
\hline & Education & 3.63 & 1,46 & $.063^{+}$ & .07 & & & \\
\hline \multirow[t]{3}{*}{ Brixton z-score } & Model & 4.95 & 3,40 & $.005^{*}$ & .27 & $<.001^{*}$ & .179 & $.027^{*}$ \\
\hline & Group & 7.34 & 2,40 & $.002 *$ & .27 & & & \\
\hline & Education & 0.49 & 1,40 & .488 & .01 & & & \\
\hline \multirow[t]{3}{*}{ PPT z-score } & Model & 4.29 & 3,41 & $.010^{*}$ & .24 & $.003^{*}$ & .519 & $.029 *$ \\
\hline & Group & 5.11 & 2,41 & $.010^{*}$ & .20 & & & \\
\hline & Education & 3.85 & 1,41 & $.056^{\dagger}$ & .09 & & & \\
\hline
\end{tabular}

*significant at the .05 level. ANCOVA = analysis of covariance, DF = degrees of freedom, SZ+FTD = schizophrenia with formal thought disorder, SZ-FTD = schizophrenia without formal thought disorder, TROG-2 = Test for Reception of Grammar, BNT = Boston Naming Test, PPT = Pyramids and Palm Trees. 